\title{
PENGARUH SENAM SEMANGAT PAGI (SSP) TERHADAP PENINGKATAN KEBUGARAN SISWA KELAS XI SMAN 4 SIDOARJO
}

\author{
Suharti ${ }^{1}$ dan Eka Kurnia Darisman ${ }^{2}$ \\ 1,2Universitas PGRI Adi Buana Surabaya \\ E-mail: atikpko@gmail.com ${ }^{1}$,ekakurniadarisman68@gmail.com²
}

Diterima: 31 Oktober 2017; Lolos: 16 November 2017; Dipublikasikan: 16 November 2017

\begin{abstract}
Abstrak
Senam Semangat PAGI, adalah salah satu variasi senam yang diciptakan oleh tim kreasi Senam Semangat PAGI Universitas PGRI Adibuana Surabaya. Senam ini diharapkan dapat meningkatkan kebugaran tubuh dan fungsi-fungsi fisiologis manusia. Tujuan dari penelitian ini adalah untuk mengetahui dan mendeskripsikan apakah ada pengaruh Senam Semangat PAGI (SSP) terhadap tingkat kebugaran siswa kelas XI di SMAN 4 Sidoarjo". Jenis penelitian ini adalah penelitian eksperimen, rancangan penelitian ini menggunakan one group pretest - postest design, dan analisis data menggunakan Anova. Adapun data yang dikumpulkan dalam penelitian ini adalah menggunakan metode TKJI. Selanjutnya data hasil penelitian dianalisis dengan menggunakan bantuan SPSS versi 18. Siswa sebelum melakukan SSP sebesar 131,15 sedangkan siswa setelah melakukan SSP sebesar 148,70. Selanjutnya analisis statistik Uji-T didapat nilai $t_{\text {hitung }}$ sebesar 4,703 lebih besar dari $t_{\text {tabel }}=3,435$. Dari hasil tersebut dapat disimpulkan bahwa terdapat Pengaruh Senam Semangat PAGI terhadap tingkat kebugaran siswa kelasXI di SMAN 4 sebesar $13 \%$.
\end{abstract}

Kata kunci: Senam Semangat PAGl, tingkat kebugaran, kebugaran jasmani.

THE INFLUENCE OF SENAM SEMANGAT PAGI (SSP) ON THE IMPROVEMENT OF FITNESS STUDENT CLASS XI SMAN 4 SIDOARJO

\begin{abstract}
Senam Semangat Pagi, is one of the variations of gymnastics created by the team creations gymnastics morning morning university PGRI Adi Buana Surabaya. This gymnastics is expected to improve body fitness and physiological functions. The purpose of this research is: to know and to describe whether there is influence of Senam Semangat Pagi (SSP) to fitness level of student of class XI in SMAN 4 Sidoarjo ". The type of this research is experimental research. The research design uses one group pretest - posttest design, and data analysis using anova analysis. The data collected in this research is using TKJI test. Furthermore, the data of the research results are analyzed using SPSS 18 series. Students before doing Senam Semangat Pagi (SSP) of 131.15 while students after doing Senam Semangat Pagi (SSP) for 148.70. Furthermore, the statistical analysis of $T$ test also can be calculated by 4.703 bigger than $t_{\text {table }}=3.435$ From these results can be concluded that there is Influence Senam Semangat Pagi (SSP) to the level of fitness class XI students in SMAN 4 of $13 \%$.
\end{abstract}

Keywords: Senam Semangat Pagi, fitness level, physical fitness.

\begin{tabular}{lll}
\hline Email & :atikpko@gmail.com & \\
& ekakurniadarisman68@gmail.com & \\
& C2017 UN PGRI Kediri \\
No Handphone $: 085749451298$ & p-ISSN: 2548-7833 \\
& e-ISSN: 2477-3379
\end{tabular}


Suharti ${ }^{1}$ dan Eka Kurnia Darisman ${ }^{2}$

Pengaruh Senam Semangat Pagi (SSP) terhadap Peningkatan Kebugaran Siswa Kelas XI SMAN 4 Sidoarjo

\section{PENDAHULUAN}

Olahraga adalah segala kegiatan yang sistematis untuk mendorong, membina, serta mengembangkan potensi jasmani, rohani, dan sosial (UU Republik Indonesia Nomor 3 Tahun 2005 dan peraturan pemerintah Tahun 2007 Tentang Sistem Keolahragaan Nasional). Dalam melakukan olahraga tidak mengenal usia dari mulai kalangan usia anakanak, usia remaja, muda, sampai kalangan tua. Selain itu mereka juga mempunyai maksud dan tujuan yang bermacam-macam. Ada yang sekedar untuk menjaga kebugaran serta kebugaran jasmani misalnya dengan lari-lari kecil gerak jalan ataupun dengan melakukan senam kebugaran jasmani.

Penyebab utama penurunan kebugaran jasmani siswa sekarang ini adalah karena mereka kurang aktif dalam bergerak. Hampir semua peralatan yang diperlukan manusia saat ini dirancang otomatis.Sehingga banyak pekerjaan dapat dilakukan tanpa harus mengeluarkan tenaga yang besar.Bila ingin menuju ke suatu tempat, siswa hanya perlu mengendarai mobil, sepeda motor, maupun alat transportasi lainnya. Siswa juga cenderung lebih banyak menonton televisi, bermain game online yang telah banyak menyita waktu seharian duduk di depan komputer kegiatan tersebut telah banyak memanjakan siswa, sehingga menyebabkan kurangnya aktivitas gerak, terlebih kepada anak dan remaja yang sedang dalam pertumbuhan. Jika keadaan ini berlangsung lama maka bisa memungkinkan terjadinya obesitas ataupun penyakit akibat kurangnya aktivitas gerak.

Senam dapat meningkatkan kebugaran tubuh dan fungsi-fungsi fisiologis. Karena manusia yang sehat merupakan sumber daya yang dibutuhkan dalam pembangunan serta menjadi modal dasar dalam mewujudkan cita-cita bangsa. Selain itu olahraga yang mempunyai prestasi tinggi akan membawa nama bangsa dimata dunia internasional.Senam Semangat PAGI, adalah salah satu variasi senam yang diciptakan oleh tim kreasi Senam Semangat PAGI Universitas PGRI Adibuana Surabaya. Variasi Senam Semangat PAGI ini juga pernah 
Suharti ${ }^{1}$ dan Eka Kurnia Darisman ${ }^{2}$

Pengaruh Senam Semangat Pagi (SSP) terhadap Peningkatan Kebugaran Siswa Kelas XI SMAN 4 Sidoarjo

terlibat dalam pemecahan rekor MURI oleh Universitas PGRI Adibuana Surabaya pada tanggal 30 Mei 2015 silam. Gerakan - gerakan dalam senam ini merepresentasikan semangat PAGI yang menjadi jargon utama Universitas PGRI Adibuana Surabaya, sebagai contoh dalam gerakan 4 adalah representasi dari kata Gigih dengan gerakan kedua tangan mengepal keatas.

Kendala umum yang ditemui berdasarkan observasi awal peneliti adalah kurangnya aktivitas gerak pada siswa. Kegiatan sehari-hari disekolah dengan lebih banyak kegiatan di dalam kelas yang cenderung siswa tidak memiliki aktivitas fisik yang melelahkan. Hal ini terbukti karena siswa hanya melakukan aktivitas gerak pada saat pelajaran pendidikan jasmani olahraga saja, berdasakan pembahasan di atas peneliti ingin mengkaji dan mengetahui tentang Pengaruh Senam Semangat PAGI (SSP) Terhadap Peningkatan Kebugaran Siswa Kelas XI di SMAN 4 Sidoarjo.

\section{Ruang Lingkup dan Pembatasan Masalah}

Dalam penelitian ini akan dijelaskan arah penelitian, sehingga tidak terjadi salah penafsiran. Untuk memperjelas arah penelitian, maka akan diuraikan sebagai berikut:

1. Pada penelitian ini peneliti hanya akan membahas tentang Pengaruh Senam Semangat PAGI (SSP) Terhadap Tingkat Kebugaran Siswa.

2. Sampel penelitian ini terbatas pada siswa kelas XI SMAN 4 Sidoarjo.

\section{Rumusan Masalah}

Berdasarkan uraian latar belakang di atas, maka penelitian ini ingin mengetahui tentang "Apakah Senam Semangat PAGI (SSP) mempunyai pengaruh terhadap tingkat kebugaran siswa kelas XI di SMAN 4 Sidoarjo?".

\section{Manfaat Penelitian}

Hasil dari penelitian ini diharapkan bermanfaat dalam

1. Secara teori 
a. Sebagai bahan bagi SMAN 4 Sidoarjo dalam membina dan meningkatkan kebugaran jasmani siswa.

b. Sebagai bahan masukan bagi orang tua siswa dalam menjaga dan meningkatkan kebugaran jasmani siswa.

c. Sebagai bahan masukan bagi penulis, siswa, guru maupun pembaca tentang pentingnya senam kebugaran jasmani.

2. Secara praktis

a. Sebagai bahan acuan bagi sekolah guna mengupayakan pelaksanan Senam Semangat PAGI (SSP) demi mengoptimalkan kebugaran jasmani siswa.

b. Sebagai masukan bagi guru penjas agar Senam Semangat PAGI (SSP) dapat dilaksanakan dengan rutin guna menambah tingkat kebugaran jasmani siswa.

c. Sebagai masukan agar pihak sekolah selalu memperhatikan tentang kebugaran jasmani siswa.

\section{METODE PENELITIAN}

\section{Rancangan Penelitian}

Dalam penelitian ini peneliti menggunakan jenis penelitian dengan menggunakan desain eksperimen one group pretest-posttest design. Dalam penelitian ini peneliti mengadakan observasi sebanyak dua kali yaitu sebelum dan sesudah, sebelum disebut pretest, sedangkan observasi yang dilakukan sesudah disebut posttest. Adapun model rancangan penelitian secara ilustrasi dapat dilihat dalam bagan berikut:

Tabel 1 Model rancangan penelitian

\begin{tabular}{cccc}
\hline Kelompok & pretest & perlakuan & posstest \\
\hline Eksperimen & $\mathrm{O} 1$ & $\mathrm{X}$ & $\mathrm{O} 2$
\end{tabular}

Keterangan :

$\mathrm{X} \quad=$ Perlakuan atau treatment

$01=$ Nilai pretest (sebelum diberi perlakuan)

$\mathrm{O} 2$ = Nilai posstest (sesudah diberikan perlakuan)

(Sugiyono, 2013:124) 
Suharti ${ }^{1}$ dan Eka Kurnia Darisman ${ }^{2}$

Pengaruh Senam Semangat Pagi (SSP) terhadap Peningkatan Kebugaran Siswa Kelas XI SMAN 4 Sidoarjo

\section{Populasi}

Populasi merupakan suatu kelompok besar dari subjek penelitian, adapun yang dijadikan sebagai populasi dalam penelitian ini adalah siswa kelas XI SMAN 4 Sidoarjo yang berjumlah 200 siswa. Alasan pengambilan populasi peneliti di sekolah tersebut adalah untuk memudahkan cara pengambilan data di sekolah tersebut.

\section{Sampel}

Dalam penelitian ini peneliti menggunakan sampel jenuh. Adapun sampel yang diambil dalam penelitian ini sebanyak 27 siswa. kelas XI SMAN 4 Sidoarjo.

\section{Teknik pengumpulan data}

Untuk memperoleh data yang diperlukan dan dipergunakan alat tes pengukuran yang menurut Nurhasan (1986:16), "tes dan pengukuran merupakan bagian yang integral dari suatu proses evaluasi kegiatan belajar mengajar khususnya dalam proses pengumpulan data. Kegiatan pengumpulan data adalah proses pengukuran".

Dalam penelitian ini perlu menggunakan metode atau cara agar diperoleh suatu data yang diinginkan. Di dalam pengumpulan data harus disesuaikan dengan jenis data yang dikumpulkan. Adapun data yang dikumpulkan dalam penelitian ini adalah menggunakan metode tes TKJI yang terdiri beberapa komponen yaitu, tes lari pendek 40 meter, tes gantung siku, baring duduk selama 30 detik, loncat tegak (Fenanlampir \& Muhyi, 2015) Dengan treatment SSP yang bertujuan untuk mengukur tingkat kebugaran siswa. Dan masing-masing siswa melakukan kedua rangkaian tersebut.

\section{Instrumen Penelitian}

Instrumen penelitian adalah merupakan sebuah alat yang digunakan untuk mengumpulkan data atau informasi yang bermanfaat untuk menjawab permasalahan peneliti. Instrumen sebagai alat pada waktu peneliti yang menggunakan suatu metode. Dalam penelitian ini yang digunakan penulisan dalam mendapatkan data yang valid adalah 
Pengaruh Senam Semangat Pagi (SSP) terhadap Peningkatan Kebugaran Siswa Kelas XI SMAN 4 Sidoarjo

berupa lapangan sekolah, stopwatch, peluit, alat tulis, speaker dengan beberapa rangkaianan yaitu:

1. Tes TKJI yang terdiri beberapa komponen yaitu:

a. Tes lari pendek 40 meter untuk mengukur kecepatan.

b. Tes gantung siku 30 detik untuk mengukur kekuatan, ketahanan otot lengan, dan otot bahu.

c. Tes baring duduk 30 detik untuk mengukur kekuatan dan ketahanan otot perut.

d. Tes loncat tegak untuk mengukur daya ledak otot kaki. (Fenanlampir \& Muhyi, 2015)

2. Penerapan treatment pola SSP di sekolah selama 2 bulan

\section{Teknik analisis data}

Data yang diperoleh dikumpulkan setelah melakukan tes pretest dan posttest, maka disusun dan dianalisis. Setelah data diperoleh dari hasil tes dan pengumpulan data, setelah terkumpul kemudian diadakan analisis data.Untuk memperoleh kesimpulan hasil penelitian yang disahkan dalam penelitian ini, diperlukan metode analisis statistik. Dengan analisis statistik maka akan memberikan efisiensi dan efektivitas kerja karena dapat membuat data yang lebih ringkas buktinya dengan rumus yang digunakan dalam menghitung efektifitas treatmentadalah :

$$
\mathrm{t}=\frac{\mathrm{Md}}{\sqrt{\frac{\sum \mathrm{X}^{2} \mathrm{~d}}{\mathrm{~N}(\mathrm{~N}-1)}}}
$$

Keterangan :

$\mathrm{Md}=$ mean dari perbedaan pre-test dengan

$$
\text { post-test }
$$

$\boldsymbol{\Sigma} \mathrm{x}^{2} \mathrm{~d}=$ jumlah kuadrat deviasitujuan untuk

$\mathrm{N}$ = subjek pada sampel

d.b. = ditentukan dengan $\mathrm{N}-1$

(Ali Maksum, 2009:79)

Uji-t ini disebut the one group desain yang bertujuan untuk mengetahui efektifitas treatment apakah terdapat peningkatan yang 
Suharti ${ }^{1}$ dan Eka Kurnia Darisman ${ }^{2}$

Pengaruh Senam Semangat Pagi (SSP) terhadap Peningkatan Kebugaran Siswa Kelas XI SMAN 4 Sidoarjo

segnifikan pengaruh senam SSP dari hasil pretest sebelum diberi perlakuan senam SSP ke posttest setelah diberikan perlakuan senam SSP.

\section{HASIL DAN PEMBAHASAN}

\section{Hasil}

Berdasarkan data dari hasil penelitian dapat diketahui hasil pretest Test Kesegaran Jasmani Indonesia (TKJI) Siswa kelas XI SMA 4 Sidoarjo bahwa sebanyak 5 siswa kategori baik dengan presentase 19\%, sebanyak 13 siswa kategori sedang dengan presentase 48\%,sebanyak 9 siswa kategori kurang dengan presentase 33\%,dan tidak ada siswa kategori kurang sekali. Dari hasil pretest 27 siswa anak tersebut dapat diketahui bahwa siswa paling banyak berkategori sedang dengan presentase $48 \%$.

Dari hasil penelitian dapat diketahui bahwa 11 siswa berkategori baik dengan persentase $41 \%$,sebanyak 12 siswa berkategori sedang dengan persentase $44 \%$ dan sebanyak 4 siswa berkategori kurang dengan persentase 15\% Dari hasil tersebut bisa diketahui bahwa siswa paling banyak berkategori sedang yaitu 12 siswa dengan persentase $44 \%$.

\section{Pengujian Hipotesis}

Disini akan dianalisa pengaruh Senam Semangat PAGI di sekolah terhadap peningkatan kebugaran jasmani siswa. Pengolahan data yang digunakan untuk mengetahui signifikan atau tidaknya, menggunakan teknik pengolahan data uji t. Pengolahan data yang dilakukan dengan memakai SPSS.

Dari hasil tersebut dapat diketahui deskripsi hasil Tes Kesegaran Jasmani Indonesia (TKJI) pretest di dapat skor rata-rata sebesar 131.15 dengan variance 1.243 standart deviasi sebesar 35.262 nilai minimum 80 dan nilai maksimum 198.

Dari hasil posttest di dapat skor rata-rata 148.70 dengan variance 1.299 standart deviasi sebesar 36.047 nilai minimum 96 dan nilai maksimum 216.

Perbedaan hasil antara sebelum dan sesudah penerapan senam pagi di sekolah adalah sebagai berikut: skor rata-rata sebesar 17.55 
Suharti ${ }^{1}$ dan Eka Kurnia Darisman ${ }^{2}$

Pengaruh Senam Semangat Pagi (SSP) terhadap Peningkatan Kebugaran Siswa Kelas XI SMAN 4 Sidoarjo

variance 0.056 standart deviasi sebesar 0.785 beda nilai minimum 16 dan nilai maksimum 18.

\section{Pembahasan}

Sesuai dengan rumusan masalah, tujuan dan hasil penelitian tentang pengaruh Senam Semangat PAGI terhadap peningkatan kebugaran jasmani siswa kelas XI SMA 4 Sidoarjo, diketahui bahwa hasil dari penelitian tersebut terdapat peningkatan kebugaran jasmani siswa setelah diadakannya Senam Semangat PAGI.

Ini terbukti dari rata-rata hasil Tes Kesegaran Jasmani Indonesia (TKJI) pretest sebesar 131.15 sedangkan postest 148.70. Selanjutnya analisis statistik Uji $\mathrm{T}$ juga didapatkan Nilai hitung sebesar 4.703 lebih besar dari $\mathrm{T}$ tabel $=3.435$, sehingga dapat disimpulkan bahwa terdapat peningkatan tingkat kesegaran jasmani siswa kelas XI SMA 4 Sidoarjo.

Selanjutnya akan dibahas penguraian penelitian tentang pengaruh Senam Semangat PAGI terhadap peningkatan kebugaran jasmani siswa kelas XI SMA 4 Sidoarjo. Aktifitas Senam Semangat PAGI dapat merangsang kerja jantung paru dan peredaran darah. Peningkatan daya tahan dapat dijadikan sebagai indikator tunggal untuk menentukan tingkat kebugaran jasmani seseorang antara lain dengan pengukuran lari 40 meter. Latihan Senam Semangat PAGI dengan takaran yang cukup dapat meningkatkan kekuatan otot. Peningkatan kekuatan otot dapat dijadikan sebagai indikator untuk menentukan tingkat kebugaran jasmani seseorang antara lain dengan pengukuran tes angkat tubuh dan baring duduk. Beban yang digunakan tidak selamanya merupakan beban dari luar saja, tetapi beban latihan dapat pula berupa badan itu sendiri terutama bagi yang masih muda dan pemula. Latihan Senam Semangat PAGI dengan takaran yang cukup dapat meningkatkan kecepatan. Peningkatan kecepatan dapat dijadikan sebagai indikator untuk menentukan tingkat kebugaran jasmani seseorang antara lain dengan pengukuran lari 40 meter. Latihan Senam Semangat PAGI dengan takaran yang cakup dapat meningkatkan kelincahan dan daya ledak. Peningkatan kecepatan dapat dijadikan sebagai indikator untuk menentukan tingkat kebugaran jasmani 
Suharti ${ }^{1}$ dan Eka Kurnia Darisman ${ }^{2}$

Pengaruh Senam Semangat Pagi (SSP) terhadap Peningkatan Kebugaran Siswa Kelas XI SMAN 4 Sidoarjo

seseorang antara lain dengan pengukuran lompat tegak. Sesuai dengan data yang terkumpul pretest dan Posttest mengalami peningkatan.

Setiap kali orang melakukan olahraga atau melakukan kegiatan fisik dengan gerakan yang berulang-ulang seperti memantul-mantulkan anggota badan, maka akan terjadi peningkatan elastisitas otot. latihan untuk sendi dengan latihan peregangan yaitu dengan menggerakan anggota tubuh secara berirama yang menyerupai latihan Senam Semangat PAGI. Latihan Senam Semangat PAGI telah memperlihatkan perubahan terhadap kelentukan sendi. Setelah melakukan selama 2 bulan dengan lama latihan 15 menit setiap kali latihan. Latihan Senam Semangat PAGI apabila dilakukan secara teratur dan sistematis serta dengan memperhatikan prinsip-prinsip latihan, hasilnya akan berpengauh bagi kesehatan dan kesegaran jasmani ternyata adalah benar.

Aktifitas Senam Semangat PAGl yang dilakukan siswa di jam sebelum masuk kelas telah membuat siswa kelas XI SMA 4 Sidoarjo semakin aktif, yang tadinya hanya duduk-duduk sambil bermain handphone dan bercanda di kelas/kantin, setelah ada penerapan aktifitas senam di jam sebelum kegiatan belajar membuat siswa semakin bersemangat mengikuti kegiatan belajar, karena dalam keadaan yang segar dan sehat membuat siswa tidak mengantuk saat mengikuti pelajaran. Apabila gerakan Senam Semangat PAGI ini dilakukan secara keseluruhan dan dengan dosis atau takaran tertentu, sudah dapat dipastikan bahwa kesehatan dan kesegaran jasmani pelakunya akan lebih meningkat, sehingga pembangunan bangsa yang kita dambakan akan lebih terjamin.

\section{KESIMPULAN DAN SARAN}

\section{Kesimpulan}

Hasil penelitian tentang pengaruh pelatihan Senam Semangat PAGI pada siswa kelas XI SMAN 4 Sidoarjo adalah sebagai berikut: 
Suharti ${ }^{1}$ dan Eka Kurnia Darisman ${ }^{2}$

Pengaruh Senam Semangat Pagi (SSP) terhadap Peningkatan Kebugaran Siswa Kelas XI SMAN 4 Sidoarjo

"Pemberian pelatihan Senam Semangat PAGI berpengaruh signifikan dengan persentase sebesar $13 \%$ terhadap peningkatan kebugaran siswa kelas XI SMA Negeri 4 Sidoarjo".

\section{Saran}

Adapun saran yang ingin peneliti sampaikan sesuai dengan hasil penelitian di atas adalah:

1. Perlu penelitian lebih lanjut mengenai latihan Senam Semangat PAGI dengan menambah frekuensi dan intesitas latihan dengan jumlah dan sampel yang berbeda.

2. Bagi para pelatih atau guru agar dalam menyusun program latihan harus memperhatikan karakteristik kemampuan setiap siswasupaya siswa mampu melaksanakan program latihan dengan baik, sehingga proses latihan berjalan lancar dan mendapatkan hasil yang maksimal.

3. Metode latihan Senam Semangat PAGI dapat direkomendasikan dan diterapkan pada program latihan untuk meningkatkan kebugaran tubuh.

\section{DAFTAR PUSTAKA}

Arikunto, Suharsimi. 2013. Dasar-Dasar Evaluasi Pendidikan, Jakarta: PT Bumi Aksara.

Cholik, Toho. Muhyi, Muhammad. \& Fenanlampir, Albertus. 2011 .Berkarakter Dengan Berolahraga, Berolahraga Dengan Berkarakter. Surabaya: SPORT media.

Departemen Pendidikan Naional. 2004. Pedoman Dan Pengembangan Olahraga Usia Dini. Jakarta:Departemen Pendidikan Naional.

Fenanlampir, Albertus \& Muhyi, Muhammad. 2015 .Tes \& Pengukuran Dalam Olahraga. Yogyakarta: CV ANDI OFFSET.

Gempur. 2005. Metodologi penelitian. Jakarta: Prestasi Pustaka publisher.

Imam. 2012. Pengaruh Senam Pagi Terhadap Peningkatan Kebugaran Jasmani Siswa Kelas XII SMP Negeri 5 Mojokerto. Skripsi Sarjana Pendidikan: Universitas PGRI Adi Buana Surabaya.

Muhajirin. 2006. Pendidikan Jasmani Olahraga \& Kesehatan. Bandung: Yudhistira.

Santika. 2012. Biomekanika Olahraga. Surabaya : Universitas PGRI Adi Buana Surabaya. 
Suharti ${ }^{1}$ dan Eka Kurnia Darisman ${ }^{2}$

Pengaruh Senam Semangat Pagi (SSP) terhadap Peningkatan Kebugaran Siswa Kelas XI SMAN 4 Sidoarjo

Sugiyono. 2013. Metode Penelitian Pendidikan. Bandung :ALFABETA.

Suharsimi. 2002. Prosedur Penelitian. Jakarta: Rineka Cipta.

Tisnowati dan Moekarto. 2003. Pendidikan Jasmani Dan Kesehatan UNIVERSITAS TERBUKA. 